\title{
3 Research Suare \\ Predictors of In-hospital Mortality in Patients with Acute Limb Ischemia - Lesson Learnt from A Tertiary Hospital in Jakarta
}

Suci Indriani ( $\sim$ suci_fkui02@yahoo.com )

Universitas Indonesia https://orcid.org/0000-0002-9156-0390

\section{Suko Adiarto}

Universitas Indonesia Fakultas Kedokteran

Hananto Andriantoro

Universitas Indonesia Fakultas Kedokteran

Ismoyo Sunu

Universitas Indonesia Fakultas Kedokteran

Taofan Siddiq

Universitas Indonesia Fakultas Kedokteran

\section{Raymond Pranata}

Universitas Pelita Harapan Fakultas Kedokteran

\section{Emir Yonas}

Yarsi University: Universitas Yarsi

Iwan Dakota

Universitas Indonesia Fakultas Kedokteran

\section{Research}

Keywords: acute limb ischemia, vascular, peripheral artery disease, Indonesia

Posted Date: November 13th, 2020

DOI: https://doi.org/10.21203/rs.3.rs-104591/v1

License: (1) (1) This work is licensed under a Creative Commons Attribution 4.0 International License. Read Full License 


\section{Abstract \\ Background}

This study aims to identify risk factors associated with in-hospital and 30-days mortality in patients with acute limb ischemia (ALI).

\section{Methods}

This study was a single-centered cohort enrolling a total of 160 consecutive patients with a diagnosis of ALI. The ALI diagnosis was based on clinical history, physical examination, and Doppler studies of the extremities. The main outcome of this study is in-hospital and 30-days mortality.

\section{Results}

There were a total of 170 patients involving 192 limbs with the diagnosis of ALI. Intra-aortic balloon pump (IABP) insertion (HR 3.4; 95\% $\mathrm{Cl} 1.0-11.3, \mathrm{p}=0.042$ ), no vitamin $\mathrm{E}$ treatment (HR 5.6; $\mathrm{Cl} 1.7-18.3$, 0.004), arrhythmia (HR 12.00; $\mathrm{Cl} 3.8-37.7, \mathrm{p}<0.001)$, and acute renal failure (HR 6.70; $\mathrm{Cl} 1.88-24.3, \mathrm{p}=$ 0.003) were an independent predictor of intra-hospital mortality. For 30-days mortality, the independent predictors were menopause (HR 3.2; $\mathrm{Cl} 1.16-8.85, \mathrm{p}=0.02)$; IABP insertion (HR 4.51; $\mathrm{Cl} 1.14-17.92, \mathrm{p}=$ 0.03 ); arrhythmia ( $\mathrm{HR} 0.11 ; \mathrm{Cl} 0.04-0.32, \mathrm{p}<0.001)$; bleeding requiring transfusion ( $\mathrm{HR} 3.77 ; \mathrm{Cl} 0.10-$ $14.28, p=0.05)$; and acute renal failure ( $H R 5.5 ; \mathrm{Cl} 1.79-16.95, p=0.003)$.

\section{Conclusion}

In-hospital mortality in patients with ALI remains high in our center. Several factors contributing to mortality were arrhythmia, renal failure, no vitamin E supplementation, and a history of recent cardiac operation.

\section{Introduction}

Acute limb ischemia (ALI) is one of the major vascular emergencies. Acute limb ischemia is defined as a sudden decrease in limb perfusion, threatening the limb's viability. ${ }^{1}$ Even though the incidence is not as high as acute coronary syndrome, it potentially causes disability and death if inadequately treated. The incidence of this condition is approximately 1.5 cases per 10,000 persons per year. ${ }^{2}$ Thirty-day mortality and amputation rates of $\mathrm{ALI}$ are up to $15 \%$ and $25 \%$, respectively. ${ }^{3}$

Acute limb ischemia is caused by thrombosis in situ, embolism from the heart or diseased arteries, aortic dissection, and trauma. Clinically, ALI is classified as (I) viable, (II) threatened, and (III) non-viable tissue. This classification helps to guide therapeutic decisions regarding the urgency of intervention, appropriate 
pre-intervention evaluation, and intervention modalities. ${ }^{1,4}$ The management of ALI aims to restore arterial flow and viability of the limb. Treatment for non-viable ALI is amputation, while the treatment options for viable and threatened ALI involves endovascular or surgical revascularization. Current advances of endovascular therapeutic approach in ALI management have improved overall amputation rates, but mortality rates remain high. ${ }^{5}$

Epidemiological studies on ALI are currently lacking. The incidence and outcome were estimated based on hospital registries, interventional trials, and autopsy studies. Increasing age, level of occlusion, recent myocardial infarction, pre-existing peripheral arterial disease, and cardiopulmonary class are touted to increases morbidity and mortality in patients with ALI. ${ }^{6}$ In the modern era of advanced surgical and endovascular revascularization, the prognostic factors may differ from that of prior decades. Factors affecting mortality and morbidity in patients with ALI in the modern era remains inadequately explored. This study aims to identify risk factors associated with in-hospital and 30-days mortality in patients with ALI.

\section{Methods}

\section{Study design and data collection}

This study was a single-centered cohort enrolling a total of 160 consecutive patients admitted to the National Cardiovascular Center Harapan Kita with a diagnosis of ALI between January 1, 2015 and December 31,2018 . This study is a part of the vascular registry database in the National Cardiovascular Center Harapan Kita which is the national referral center for cardiovascular diseases in Indonesia. The database includes baseline characteristics, diagnosis, comorbidities, procedures performed, and outcome. The ALI diagnosis was based on clinical history, physical examination, and Doppler studies of the extremities. The main outcome of this study is in-hospital and 30-days mortality. All patients were treated based on standard treatment of ALI based on the European Society of Cardiology Guideline on Peripheral Arterial Disease. Additional drugs are left to the discretion of the treating physician. Additional drugs are as follow: Allopurinol $1 \times 300 \mathrm{mg}$, Vitamin E $2 \times 400 \mathrm{mg}$, Pentoxifylline $1200 \mathrm{mg}$ and Sodium bicarbonate $3 \times 500 \mathrm{mg}$. Exclusion criteria were incomplete data (5\%). The study has been approved by the institutional review board of the National Cardiovascular Center Harapan Kita

\section{Statistics Analysis}

For the baseline characteristics, we classified the patients into survivor and non-survivor; Chi-Square and independent t-test analyses were performed to compare the two groups. We performed a Cox-regression analysis for univariate and multivariate analysis to identify factors associated with in-hospital and 30days mortality. Variables with p-value $<0.25$ in the univariate analysis were included in a multivariate coxregression analysis to identify the most influential factors related to in-hospital and 30-days mortality. We considered a two-sided p-value of less than 0.05 as statistically significant. All analyses were conducted using SPSS version 23.0 . 


\section{Results}

A total of 170 patients involving 192 limbs were admitted to our hospital with the diagnosis of ALI from January 1st 2015 to December 31st 2018. Ten patients were excluded due to incomplete data. Among 160 patients, $63.1 \%$ were male and the mean age was $56 \pm 13$ years old. In-hospital and 30-days mortality were $28.1 \%$ and $36.9 \%$, respectively (Fig. 1). The baseline characteristics of our study population were shown in Table 1. There are no differences between survivor and non-survivor groups in terms of age, gender, onset of ALI, and limb ischemia severity. History of recent operation and aorta involvement were higher in the non-survivor group. Ischemic sign on ECG, low hematocrit, higher creatinine level was more frequent in the non-survivor group. Survival rate was higher in patients receiving Additional treatment such as vitamin E, pentoxifylline, sodium bicarbonate. Complications such as sepsis, acute renal injury, bleeding were more frequent in the non-survivors. 
Table 1

Baseline characteristics of population study

\begin{tabular}{|c|c|c|c|}
\hline \multirow[t]{2}{*}{ Variables } & \multicolumn{2}{|l|}{ In-hospital Mortality } & \multirow[t]{2}{*}{$P$ value } \\
\hline & Non-survivor $(n=45)$ & Survivor $(n=115)$ & \\
\hline Age (years) & $58,9 \pm 9,4$ & $55,8 \pm 14,3$ & 0,115 \\
\hline Male & $28(62.2 \%)$ & $73(63.5 \%)$ & 1,000 \\
\hline Onset (hours) & $52.7 \pm 74.7$ & $92.1 \pm 111.3$ & 0.041 \\
\hline Involvement of limb & $19(42.2 \%)$ & $56(48.7 \%)$ & 0,705 \\
\hline - Right unilateral & $17(37.8 \%)$ & $6(31.3 \%)$ & \\
\hline - Left Unilateral & $9(20 \%)$ & $23(20 \%)$ & \\
\hline \multicolumn{4}{|l|}{ - Bilateral } \\
\hline Severity (Rutherford) & $8(17.8 \%)$ & $24(20.9 \%)$ & 0,330 \\
\hline-1 & $14(31.1 \%)$ & $44(38.3 \%)$ & \\
\hline - IIA & $20(44.4 \%)$ & $34(29.6 \%)$ & \\
\hline - IIIB & $3(6.7 \%)$ & $13(11.3 \%)$ & \\
\hline \multicolumn{4}{|l|}{ - III } \\
\hline Smoker & $23(51.1 \%)$ & $59(51.3 \%)$ & 1.00 \\
\hline Hypertension & $29(64.4 \%)$ & $66(57.4 \%)$ & 0,524 \\
\hline Diabetes Mellitus & $14(31.1 \%)$ & $35(30.4 \%)$ & 0.538 \\
\hline History of coronary artery disease & $22(48.9 \%)$ & $39(33.9 \%)$ & 0,116 \\
\hline History of valvular disease (mitral/aorta) & $9(20 \%)$ & $13(11.3 \%)$ & 0,151 \\
\hline History of recent cardiac operation & $15(33.3 \%)$ & $15(13 \%)$ & 0,006 \\
\hline History aortic dissection & $3(30 \%)$ & $7(12.3 \%)$ & 0.163 \\
\hline Etiology thrombosis & $23(51.1 \%)$ & $75(65.2 \%)$ & 0,143 \\
\hline Etiology embolism & $19(42.2 \%)$ & $32(27.8 \%)$ & 0,117 \\
\hline Aortic lesion & $2(4.4 \%)$ & $0(0 \%)$ & $<0,001$ \\
\hline Iliac -femoral lesion & $26(57.8 \%)$ & $62(53.9 \%)$ & 0,791 \\
\hline Poplitea-tibial lesion & $21(46.7 \%)$ & $59(51.3 \%)$ & 0,725 \\
\hline Atrial fibrillation & $8(17.8 \%)$ & $26(22.6 \%)$ & 0,648 \\
\hline Ischemic sign on ECG & $21(46.7 \%)$ & $32(27.8 \%)$ & 0,037 \\
\hline
\end{tabular}




\begin{tabular}{|c|c|c|c|}
\hline \multirow[t]{2}{*}{ Variables } & \multicolumn{2}{|l|}{ In-hospital Mortality } & \multirow[t]{2}{*}{$P$ value } \\
\hline & Non-survivor $(n=45)$ & Survivor $(n=115)$ & \\
\hline Leucocyte > 10.000 /uL & $34(77,3 \%)$ & $66(66,7 \%)$ & 0,281 \\
\hline Hemoglobin $<12 \mathrm{~g} / \mathrm{dL}$ & $22(48,9 \%)$ & $36(32,4 \%)$ & 0,081 \\
\hline Hematocrit $<34 \%$ & $24(53,3 \%)$ & $82(75,2 \%)$ & 0,013 \\
\hline Creatinine $>1.2 \mathrm{~g} / \mathrm{dL}$ & $30(68,2 \%)$ & $43(38,7 \%)$ & 0,002 \\
\hline Ejection Fraction on echocardiography (\%) & $47,6 \pm 19,6$ & $50,0 \pm 17,8$ & 0,51 \\
\hline TAPSE on echocardiography $(\mathrm{cm})$ & $1,9 \pm 0,5$ & $2,0 \pm 1,5$ & 0,484 \\
\hline Intra Arterial Thrombolytic Therapy (PIAT) & $2(4,4 \%)$ & $14(12,2 \%)$ & 0,239 \\
\hline Surgical Embolectomy & $10(22,2 \%)$ & $24(20,9 \%)$ & 1,000 \\
\hline Heparin treatment & $33(73.3 \%)$ & $91(79.1 \%)$ & 0,563 \\
\hline Pentoxifylline treatment & $30(66.7 \%)$ & $77(67,5 \%)$ & 1 \\
\hline Sodium Bicarbonate treatment & $29(65.9 \%)$ & $92(80.7 \%)$ & 0,049 \\
\hline Vitamin E Treatment & $9(20,0 \%)$ & $46(40,7 \%)$ & 0,023 \\
\hline Allopurinol Treatment & $27(60,0 \%)$ & $87(75,7 \%)$ & 0,049 \\
\hline Aspirin Treatment & $16(37,2 \%)$ & $58(51,8 \%)$ & 0,148 \\
\hline Clopidogrel Treatment & $17(37,8 \%)$ & $56(48,7 \%)$ & 0,285 \\
\hline Statin Therapy & $24(53,3 \%)$ & $67(58,8 \%)$ & 0,655 \\
\hline Septic & $14(31,1 \%)$ & $8(7 \%)$ & $<0,0001$ \\
\hline Arrhythmia & $23(51,1 \%)$ & $14(12,2 \%)$ & $<0,0001$ \\
\hline Bleeding (Gastrointestinal, cerebral) & $12(26,7 \%)$ & $9(7,80 \%)$ & 0,004 \\
\hline Acute Renal Injury & $18(40,0 \%)$ & $13(11,3 \%)$ & $<0,0001$ \\
\hline Duration of hospital stay (days) & $11 \pm 10$ & $10 \pm 8$ & 0.443 \\
\hline
\end{tabular}

Table 2 showed univariate and multivariate analysis of variables related to in-hospital mortality. In the univariate analysis, Intra-Aortic Balloon Pump (IABP) insertion, no treatment of bicarbonate sodium and vitamin $\mathrm{E}$, arrhythmia, bleeding requiring transfusion, and acute renal failure were related to in-hospital mortality. In the multivariate analysis, the predictors for in-hospital mortality were insertion of IABP (HR 3.4; 95\% Cl 1.0-11.3, $\mathrm{p}=0.042)$; no vitamin E treatment (HR 5.6; Cl 1.7-18.3, $\mathrm{p}=0.004)$; arrhythmia (HR 12.00; $\mathrm{Cl} 3.8-37.7, \mathrm{p}<0.001)$; and acute renal failure (HR 6.70; $\mathrm{Cl} 1.88-24.3, \mathrm{p}=0.003$ ). Bleeding requiring transfusion was not a significant factor. 
Table 2

Univariate and multivariate analyses of variables associated with in-hospital mortality

\begin{tabular}{|lllll|}
\hline Variables & Univariate analysis & \multicolumn{2}{l|}{ Multivariate analysis } \\
\cline { 2 - 3 } & HR $(95 \%$ Cl) & P value & HR $(95 \%$ Cl) & P value \\
\hline Age & $0.95(0.89-1.08)$ & 0.087 & & \\
\hline Atrial fibrillation & $0.11(0.007-1.743)$ & 0.118 & & \\
\hline IABP insertion & $25.80(2.5-244.52)$ & 0.006 & $3.40(1.0-11.3)$ & 0.042 \\
\hline History of Aortic dissection & $0.079(0.001-6.866)$ & 0.265 & & \\
\hline No Sodium bicarbonate therapy & $0.057(0.005-0.680)$ & 0.023 & & \\
\hline No Vitamin E therapy & $14.296(2.004-101.998)$ & 0.008 & $5.6(1.7-18.3)$ & 0.004 \\
\hline No Allopurinol therapy & $5.58(0.59-52.36)$ & 0.132 & & \\
\hline Sepsis & $0.179(0.02-1.63)$ & 0.127 & & \\
\hline Arrhythmia & $16.31(2.52-105.61)$ & 0.003 & $12.00(3.8-37.7)$ & $<.001$ \\
\hline Bleeding requiring transfusion & $59.787(1.19-2991.8)$ & 0.04 & $3.40(0.82-14.3)$ & 0.090 \\
\hline Acute renal failure & $9.01(1.11-73.27)$ & 0.04 & $6.70(1.88-24.3)$ & 0.003 \\
\hline Leukocyte $>10.000 / \mathrm{uL}$ & $0.78(0.16-3.79)$ & 0.756 & & \\
\hline Hemoglobin $>12 \mathrm{~g} / \mathrm{dL}$ & $0.38(0.02-4.92)$ & 0.458 & & \\
\hline Creatinine $>1,2$ mg/dL & $0.43(0.09-2.00)$ & 0.279 & & \\
\hline
\end{tabular}

Table 3 showed the result of univariate and multivariate analysis of variables related to 30-days mortality. In the univariate analysis, risk factors of menopause in women, acute renal failure, arrhythmia, and bleeding requiring transfusion were related to 30 -days mortality. In the multivariate analysis, the predictors for 30-days mortality were menopause (HR 3.2; $\mathrm{Cl} 1.16-8.85, \mathrm{p}=0.02$ ); IABP insertion (HR 4.51; $\mathrm{Cl} 1.14-17.92, \mathrm{p}=0.03$ ); arrhythmia ( $\mathrm{HR} 0.11 ; \mathrm{Cl} 0.04-0.32, \mathrm{p}<0.001)$; bleeding requiring transfusion (HR 3.77 ; $\mathrm{Cl} 0.10-14.28, \mathrm{p}=0.05)$; and acute renal failure (HR 5.5; $\mathrm{Cl} 1.79-16.95, \mathrm{p}=0.003)$. 
Table 3

Univariate and multivariate analyses of variables associated with 30-days mortality

\begin{tabular}{|lllll|}
\hline Variables & \multicolumn{3}{l}{ Univariate analysis } & \multicolumn{2}{l|}{ Multivariate analysis } \\
\cline { 2 - 5 } & HR (95\% Cl) & P value & HR (95\% Cl) & P value \\
\hline Onset & $1.00(0.99-1.01)$ & 0.17 & & \\
\hline Rutherford severity & $0.36(0.071-1.88)$ & 0.091 & & 0.02 \\
\hline Menopause & $4.17(1.20-14.46)$ & 0.024 & $3.20(1.16-8.85)$ & 0.03 \\
\hline IABP insertion & $3.6(0.78-16.47)$ & 0.099 & $4.51(1.14-17.92)$ & \\
\hline No vitamin E treatment & & 0.404 & & \\
\hline Acute Renal Failure & $4.13(1.05-16.33)$ & 0.043 & & \\
\hline Arrhythmia & $0.18(0.05-0.62)$ & 0.007 & & 0.001 \\
\hline Sepsis & $0.179(0.02-1.63)$ & 0.127 & & 0.05 \\
\hline Arrhythmia & $16.31(2.52-105.61)$ & 0.003 & $0.11(0.04-0.32)$ & \\
\hline Bleeding requiring transfusion & $59.787(1.19-2991.8)$ & 0.04 & $3.77(0.10-14.28)$ & \\
\hline Acute renal failure & $9.01(1.11-73.27)$ & 0.04 & $5.50(1.79-16.95)$ & 0.003 \\
\hline Creatinine $>1,2$ mg/dL & $0.77(0.28-2.10)$ & 0.61 & & \\
\hline
\end{tabular}

\section{Discussion}

Despite recent advances in ALI management, it is still a challenging issue associated with high mortality. The in-hospital mortality rate in our institution was $28.1 \%$ in the past 3 years (2015-2018). This number was larger than other studies, which is likely due to the late presentation of patients in our cohort. Clason et al. reported that the 30-days mortality rate among ALI patients was around $26 \%{ }^{6}$ Baril et al. showed that the in-hospital mortality for ALI declines from $12.1 \%$ in 1998 to $9.0 \%$ in $2009(P<.001)$ in the United States Medicare population. ${ }^{5}$ Endovascular therapy for the treatment of ALI is increasingly used and contributes to mortality reduction in the Medicare population. In our institution, the percentage of patients undergoing endovascular therapy and surgical embolectomy was only $0 \%$ and $21.3 \%$, respectively. The remainder of the patients was only managed by anticoagulation without primary reperfusion during hospitalization. The choice of therapeutic modalities was not associated with mortality in our patients. A meta-analysis demonstrated no significant difference in short-term and 12-months mortality, limb amputation, and recurrent ischemia in endovascular or surgical approach in ALI. ${ }^{7}$

There were differences in the subjects' baseline characteristics regarding history of cardiac operation, aortic lesion, and ischemic sign on ECG between survivor and non survivor groups (P-value: 0.006, < 0.001 , and 0.037 respectively). These findings describe the degree of atherosclerotic burden and vascular 
damage in a patient's body. Patients who presented with any of these history have higher mortality risk. According to several studies, cardiopulmonary complications account for the majority cause of death. Approximately 15 to 20 percent of patients die within one year of presentation of their limb ischemia, usually from the medical illnesses that predispose them to acute limb ischemia. ${ }^{1,8,9}$

Most of the studies reported the risk factors associated with 30-days and 1-year mortality. The data on factors that contribute to in-hospital mortality is currently lacking. This study showed that in-hospital development of cardiac arrhythmias and acute renal failure were associated with mortality. Previously, 30-days mortality and amputation were attributed to several factors, including increasing age, level of occlusion, recent myocardial infarction, pre-existing peripheral arterial disease, and cardiopulmonary functional class. ${ }^{6}$ United States Medicare registries indicate that patients with advanced age, chronic renal failure, dementia, cancer, and atrial fibrillation have higher 30-days mortality. ${ }^{5}$ In our registry, all of these factors did not contribute to in-hospital mortality.

History of recent cardiac operation is one of the factors contributing to in-hospital mortality. In this registry, 30 from 160 patients had ALI after CABG or valve surgery. Most of these patients have a history of IABP insertion prior to or after the procedure. Approximately $32.6 \%$ of patients with ALI who underwent IABP insertion died in-hospital. Allen et al. found that IABP insertion to cardiac surgery patients is a strong risk factor for acute leg ischemia. Morbidity and mortality of ALI after cardiac surgery were $92 \%$ and $46 \%$, respectively. ${ }^{10}$ Folkert et al. showed that IABP insertion leads to a five-fold increase in ALI. ${ }^{11}$ It is interesting to note that vascular complications, including acute limb ischemia remains a significant risk associated with IABP, occurring in $6-25 \%$ of cases. IABP insertion could cause leg ischemia from several mechanisms, insertion to femoral branches rather than the common femoral artery could cause limb ischemia, improper insertion/needle puncture, which is too low is the most common cause of ischemic complication during IABP. ${ }^{12,13}$

Lethality in ALI is attributed to the reperfusion injury. After occlusion and tissue ischemia, blood flow restoration may paradoxically exacerbate prior ischemic injury by an overt inflammatory response that promotes local tissue destruction and remote organ dysfunction. ${ }^{14,15}$ Reperfusion to severely ischemic muscles may induce the release of toxic metabolites such as potassium, free radicals, and myoglobin, culminating in a life-threatening systemic complications including renal, cardiac and pulmonary failure. ${ }^{16,17}$ Reperfusion to rhabdomyolytic muscle induces the release of myoglobin, causing acute tubular necrosis. Reperfusion also induces overflow of intracellular potassium and hydrogen ions due to the destroyed potassium-sodium pump causing metabolic acidosis and cardiac arrhythmia. ${ }^{16}$ Acute renal injury and life-threatening arrhythmia are amongst the fatal ALI complications. In our registry, acute renal injury and fatal arrhythmia contributed significantly to in-hospital mortality.

Vitamin $\mathrm{E}$ has been known for its antioxidant effect and reducing ischemic reperfusion injury. Vitamin $\mathrm{E}$ can inactivate reactive oxygen species (ROS), where its production increased after reperfusion occurred. Reperfusion will increase ROS release, infiltration of inflammatory cells and humoral mediators which 
further potentiates cellular damage. ${ }^{22}$ Initiation and propagation of ischemic-reperfusion injury depend upon transcription factor activation, which is responsible for the induction of inflammatory genes required for rapid production of some proteins such as cytokine, adhesion molecules, complement factors, and NO synthase. ${ }^{23,24}$ Vitamin E also affects the regulator of signal transduction and modification of NF-KB as predominant transcription factor activation during reperfusion. ${ }^{25} \mathrm{~A}$ vitamin $\mathrm{E}$ pre-treatment in a model of ischemic-reperfusion of lower limb muscle of patients undergoing aortic cross-clamp during surgical repair of abdominal aortic aneurysm was shown to prevent the accumulation of neutrophils within ischemic and reperfused muscle by reducing expression of endothelial adhesion proteins such as E-selectin and ICAM-1. ${ }^{26}$ In patients undergoing aortic aneurysm resection, vitamin E administration was associated with reduced oxidative skeletal muscle damage secondary to ischemiareperfusion injury. ${ }^{27}$

In our institution, we administered $200 \mathrm{mg}$ of Vitamin E per day in patients with ALI to reduce ischemiareperfusion injury; however, we cannot provide it for all patients due to insurance reimbursement cap. Surprisingly, our study showed that a no vitamin E treatment in the acute phase of ALI causes a six-fold increased risk for in-hospital mortality. Arato et al. demonstrate that $200 \mathrm{mg}$ vitamin E administration in patients undergoing lower limb vascular surgery, starting from preoperative day until seven days postoperative reduced the level of oxidative stress (lipid peroxidation, antioxidant enzymes) generated after ischemia-reperfusion insult. Vitamin E administration could also reduce white blood cell activation (MPO activation, free-radicals production, expression of adhesion molecules), reverse prooxidant-antioxidant balance and the consecutive local inflammatory process during early reperfusion compare to placebo. ${ }^{28}$ To the best of the authors' knowledge, this is the first study to demonstrate the benefit of Vitamin $\mathrm{E}$ supplementation in ALI patients. Further randomized controlled trials should be performed to generate more concrete evidence.

In-hospital morbidity of ALI found in our hospital mainly consists of sepsis, arrhythmia (tachy/bradyarrythmia), bleeding (gastrointestinal and cerebral), acute renal injury, and their proportion was significantly higher in non-survivor group. Primary amputation rate during hospitalization is about $20 \%$. We also observed that the number of bleeding correlates with the number sepsis in both survivor and non-survivor groups of in-hospital mortality analysis. Sepsis is one of the most common causes of disseminated intravascular coagulation, which would most likely give way to major bleeding requiring blood transfusion. This explains why bleeding was an independent predictor of mortality in the multivariate analysis for in-hospital and 30-days mortality. ${ }^{29,30}$

\section{Limitation}

The registry was single-center, and the data was collected from a National Referral Hospital. There is a potential for selection bias which may explain the high mortality. The data were collected both prospective and retrospectively from medical records. Some of them have incomplete data or were lost to follow up. The treatments were based on physician discretion; nevertheless, it reflects real-world practice. 


\section{Conclusion}

In-hospital mortality in patients with ALI remains high in our center. Several factors contributing to mortality were arrhythmia, renal failure, no vitamin E supplementation, and a history of recent cardiac operation.

\section{Declarations}

Ethics approval and consent to participate

Ethical clearance approved by National Cardiovascular Center Harapan Kita Institutional Review Board.

\section{Consent for publication}

All authors read and approved final version of manuscript

\section{Availability of data and materials}

Data available upon reasonable request by journal editor

Competing interests : none

Funding : None

Acknowledgements: None

\section{Authors' contributions}

Suci Indriani : Conceptualization, Formal Analysis, Writing-Original Draft.

Suko Adiarto: Writing - Review and editing.

Hananto Andriantoro: Writing - Review and editing

Ismoyo Sunu: Writing - Review and editing

Taofan Siddiq: Writing - Review and editing

Raymond Pranata: Writing - Review and editing, Formal Analysis.

Emir Yonas: Writing - Review and editing, Formal Analysis.

Iwan Dakota: Writing - Review and editing

\section{References}


1. Creager MA, Kaufman JA, Conte MS. Acute limb ischemia. N Engl J Med. 2012;366(23):2198-2206. doi:10.1056/NEJMcp1006054

2. Norgren L, Hiatt WR, Dormandy JA, Nehler MR, Harris KA, Fowkes FGR. Inter-Society Consensus for the Management of Peripheral Arterial Disease (TASC II). J Vasc Surg. 2007;45(1 SUPPL.). doi:10.1016/j.jvs.2006.12.037

3. Rajan DK, Patel NH, Valji K, et al. Quality improvement guidelines for percutaneous management of acute limb ischemia. J Vasc Interv Radiol. 2005;16(5):585-595.

doi:10.1097/01.RVI.0000156191.83408.B4

4. Lyden SP. Endovascular treatment of acute limb ischemia: Review of current plasminogen activators and mechanical thrombectomy devices. Perspect Vasc Surg Endovasc Ther. 2010;22(4):219-222. doi:10.1177/1531003511400624

5. Baril DT, Ghosh K, Rosen AB. Trends in the incidence, treatment, and outcomes of acute lower extremity ischemia in the United States Medicare population. J Vasc Surg. 2014;60(3). doi:10.1016/j.jvs.2014.03.244

6. Clason AE, Stonebridge PA, Duncan AJ, Nolan B, Jenkins AML, Ruckley C V. Morbidity and mortality in acute lower-limb ischaemia: A 5-year review. Eur J Vasc Surg. 1989;3(4):339-343. doi:10.1016/S0950-821X(89)80071-4

7. Enezate TH, Omran J, Mahmud E, et al. Endovascular versus surgical treatment for acute limb ischemia: A systematic review \& meta-Analysis of clinical trials. Cardiovasc Diagn Ther. 2017;7(3):264-271. doi:10.21037/cdt.2017.03.03

8. Wolosker N, Kuzniec S, Gaudêncio A, et al. Arterial embolectomy in lower limbs. Sao Paulo Med J. 1996;114(4):1226-1230. doi:10.1590/s1516-31801996000400007

9. Yeager RA, Moneta GL, Taylor LM, Hamre DW, McConnell DB, Porter JM. Surgical management of severe acute lower extremity ischemia. J Vasc Surg. 1992;15(2):385-393. doi:10.1016/07415214(92)90260-F

10. Allen RC, Schneider J, Longenecker L, Kosinski AS, Smith RB, Lumsden AB. Acute lower extremity ischemia after cardiac surgery. Am J Surg. 1993;166(2):124-129. doi:10.1016/S00029610(05)81042-6

11. Folkert IW, Foley PJ, Wang GJ, et al. Impact of acute post-operative limb ischemia after cardiac and thoracic aortic surgery. J Vasc Surg. 2018;67(5):1530-1536.e2. doi:10.1016/j.jvs.2017.09.019

12. Patel JJ, Kopisyansky C, Boston B, Kuretu MLR, McBride R, Cohen M. Prospective evaluation of complications associated with percutaneous intraaortic balloon counterpulsation. Am J Cardiol. 1995;76(16):1205-1207. doi:10.1016/S0002-9149(99)80341-5

13. Barnett MG, Swartz MT, Peterson GJ, et al. Vascular complications from intraaortic balloons: Risk analysis. J Vasc Surg. 1994;19(1):81-89. doi:10.1016/S0741-5214(94)70123-7

14. Blaisdell $F$. The pathophysiology of skeletal muscle ischemia and the reperfusion syndrome: a review. Cardiovasc Surg. 2002;10(6):620-630. doi:10.1016/s0967-2109(02)00070-4 
15. Carden DL, Granger DN. Pathophysiology of ischaemia-reperfusion injury. J Pathol. 2000;190(3):255266. doi:10.1002/(SICI)1096-9896(200002)190:3<255::AID-PATH526>3.0.C0;2-6

16. Fukuda I, Chiyoya M, Taniguchi S, Fukuda W. Acute limb ischemia: contemporary approach. Gen Thorac Cardiovasc Surg. 2015;63(10):540-548. doi:10.1007/s11748-015-0574-3

17. Dick F, Li J, Giraud MN, Kalka C, Schmidli J, Tevaearai H. Basic control of reperfusion effectively protects against reperfusion injury in a realistic rodent model of acute limb ischemia. Circulation. 2008;118(19):1920-1928. doi:10.1161/CIRCULATIONAHA.108.787754

18. Swain RA, Kaplan-Machlis B. Therapeutic uses of vitamin E in prevention of atherosclerosis. Altern Med Rev. 1999;4(6):414-423. http://www.ncbi.nlm.nih.gov/pubmed/10608914.

19. Klipstein-Grobusch K, Den Breeijen JH, Grobbee DE, Boeing H, Hofman A, Witteman JCM. Dietary antioxidants and peripheral arterial disease: The Rotterdam study. Am J Epidemiol. 2001;154(2):145149. doi:10.1093/aje/154.2.145

20. Gardner AW, Bright BC, Ort KA, Montgomery PS. Dietary intake of participants with peripheral artery disease and claudication. Angiology. 2011;62(3):270-275. doi:10.1177/0003319710384395

21. Kleijnen J, Mackerras D. Vitamin E for intermittent claudication. Cochrane Database Syst Rev. 1998. doi:10.1002/14651858.cd000987

22. Boyle EM, Canty TG, Morgan EN, Yun W, Pohlman TH, Verrier ED. Treating myocardial ischemiareperfusion injury by targeting endothelial cell transcription. Ann Thorac Surg. 1999;68(5):1949-1953. doi:10.1016/S0003-4975(99)01033-4

23. Brennan P, O'Neill LAJ. Inhibition of nuclear factor $\mathrm{KB}$ by direct modification in whole cells Mechanism of action of nordihydroguaiaritic acid, curcumin and thiol modifiers. Biochem Pharmacol. 1998;55(7):965-973. doi:10.1016/S0006-2952(97)00535-2

24. Paludan SR. Synergistic action of pro-inflammatory agents: Cellular and molecular aspects. $J$ Leukoc Biol. 2000;67(1):18-25. doi:10.1002/jlb.67.1.18

25. Nakamura T, Goto M, Matsumoto A, Tanaka I. Inhibition of NF-kB transcriptional activity by atocopheryl succinate. BioFactors. 1998;7(1-2):21-30. doi:10.1002/biof.5520070104

26. Formigli L, Ibba Manneschi L, Tani A, et al. Vitamin E prevents neutrophil accumulation and attenuates tissue damage in ischemic-reperfused human skeletal muscle. Histol Histopathol. 1997;12(3):663-669. http://www.ncbi.nlm.nih.gov/pubmed/9225148.

27. Novelli GP, Adembri C, Gandini E, et al. Vitamin E protects human skeletal muscle from damage during surgical ischemia-reperfusion. Am J Surg. 1997;173(3):206-209. doi:10.1016/S00029610(97)89593-1

28. Arató E, Kürthy M, Sínay L, et al. Pathology and diagnostic options of lower limb compartment syndrome. Clin Hemorheol Microcirc. 2009;41(1):1-8. doi:10.3233/CH-2009-1145

29. Tang N, Li D, Wang X, Sun Z. Abnormal coagulation parameters are associated with poor prognosis in patients with novel coronavirus pneumonia. J Thromb Haemost. 2020;18(4):844-847. doi: $10.1111 /$ jth. 14768 
30. Levi M, Toh $\mathrm{CH}$, Thachil J, Watson HG. Guidelines for the diagnosis and management of disseminated intravascular coagulation. Br J Haematol. 2009;145(1):24-33. doi:10.1111/j.13652141.2009.07600.x

\section{Tables}

Table 1. Baseline characteristics of population study 


\begin{tabular}{|c|c|c|c|}
\hline \multirow[t]{2}{*}{ Variables } & \multicolumn{2}{|l|}{ In-hospital Mortality } & \multirow[t]{2}{*}{$P$ value } \\
\hline & Non-survivor $(n=45)$ & Survivor $(n=115)$ & \\
\hline Age (years) & $58,9 \pm 9,4$ & $55,8 \pm 14,3$ & 0,115 \\
\hline Male & $28(62.2 \%)$ & $73(63.5 \%)$ & 1,000 \\
\hline Onset (hours) & $52.7 \pm 74.7$ & $92.1 \pm 111.3$ & 0.041 \\
\hline \multicolumn{4}{|l|}{ Involvement of limb } \\
\hline - $\quad$ Right unilateral & $19(42.2 \%)$ & $56(48.7 \%)$ & 0,705 \\
\hline - $\quad$ Left Unilateral & & & \\
\hline \multirow[t]{2}{*}{ - Bilateral } & $17(37.8 \%)$ & $6(31.3 \%)$ & \\
\hline & $9(20 \%)$ & $23(20 \%)$ & \\
\hline \multicolumn{4}{|l|}{ Severity (Rutherford) } \\
\hline $\begin{array}{ll}- & 1\end{array}$ & $8(17.8 \%)$ & $24(20.9 \%)$ & 0,330 \\
\hline$-\quad \quad I A$ & $14(31.1 \%)$ & $44(38.3 \%)$ & \\
\hline$-\quad$ IIB & $20(44.4 \%)$ & $34(29.6 \%)$ & \\
\hline$-\quad$ III & $3(6.7 \%)$ & $13(11.3 \%)$ & \\
\hline Smoker & $23(51.1 \%)$ & $59(51.3 \%)$ & 1.00 \\
\hline Hypertension & $29(64.4 \%)$ & $66(57.4 \%)$ & 0,524 \\
\hline Diabetes Mellitus & $14(31.1 \%)$ & $35(30.4 \%)$ & 0.538 \\
\hline History of coronary artery disease & $22(48.9 \%)$ & $39(33.9 \%)$ & 0,116 \\
\hline History of valvular disease (mitral/aorta) & $9(20 \%)$ & $13(11.3 \%)$ & 0,151 \\
\hline History of recent cardiac operation & $15(33.3 \%)$ & $15(13 \%)$ & 0,006 \\
\hline History aortic dissection & $3(30 \%)$ & $7(12.3 \%)$ & 0.163 \\
\hline Etiology thrombosis & $23(51.1 \%)$ & $75(65.2 \%)$ & 0,143 \\
\hline
\end{tabular}




\begin{tabular}{|c|c|c|c|}
\hline Etiology embolism & $19(42.2 \%)$ & $32(27.8 \%)$ & 0,117 \\
\hline Aortic lesion & $2(4.4 \%)$ & $0(0 \%)$ & $<0,001$ \\
\hline lliac -femoral lesion & $26(57.8 \%)$ & $62(53.9 \%)$ & 0,791 \\
\hline Poplitea-tibial lesion & $21(46.7 \%)$ & $59(51.3 \%)$ & 0,725 \\
\hline Atrial fibrillation & $8(17.8 \%)$ & $26(22.6 \%)$ & 0,648 \\
\hline Ischemic sign on ECG & $21(46.7 \%)$ & $32(27.8 \%)$ & 0,037 \\
\hline Leucocyte > $10.000 / u L$ & $34(77,3 \%)$ & $66(66,7 \%)$ & 0,281 \\
\hline Hemoglobin $<12$ g/dL & $22(48,9 \%)$ & $36(32,4 \%)$ & 0,081 \\
\hline Hematocrit <34\% & $24(53,3 \%)$ & $82(75,2 \%)$ & 0,013 \\
\hline Creatinine $>1.2 \mathrm{~g} / \mathrm{dL}$ & $30(68,2 \%)$ & $43(38,7 \%)$ & 0,002 \\
\hline Ejection Fraction on echocardiography (\%) & $47,6 \pm 19,6$ & $50,0 \pm 17,8$ & 0,51 \\
\hline TAPSE on echocardiography (cm) & $1,9 \pm 0,5$ & $2,0 \pm 1,5$ & 0,484 \\
\hline Intra Arterial Thrombolytic Therapy (PIAT) & $2(4,4 \%)$ & $14(12,2 \%)$ & 0,239 \\
\hline Surgical Embolectomy & $10(22,2 \%)$ & $24(20,9 \%)$ & 1,000 \\
\hline Heparin treatment & $33(73.3 \%)$ & $91(79.1 \%)$ & 0,563 \\
\hline Pentoxifylline treatment & $30(66.7 \%)$ & $77(67,5 \%)$ & 1 \\
\hline Sodium Bicarbonate treatment & $29(65.9 \%)$ & $92(80.7 \%)$ & 0,049 \\
\hline
\end{tabular}


Vitamin E Treatment

Allopurinol Treatment

Aspirin Treatment

Clopidogrel Treatment

Statin Therapy

Septic

Arrhythmia

Bleeding (Gastrointestinal, cerebral)

Acute Renal Injury

Duration of hospital stay (days)
$9(20,0 \%)$

$46(40,7 \%)$

0,023

$27(60,0 \%)$

$87(75,7 \%)$

0,049

$16(37,2 \%)$

$58(51,8 \%)$

0,148

$17(37,8 \%)$

$56(48,7 \%)$

0,285

$24(53,3 \%)$

$67(58,8 \%)$

0,655

$14(31,1 \%)$

$8(7 \%)$

$<0,0001$

$23(51,1 \%)$

$14(12,2 \%)$

$<0,0001$

$12(26,7 \%)$

$9(7,80 \%)$

0,004

$18(40,0 \%)$

$13(11,3 \%)$

$<0,0001$

$11 \pm 10$

$10 \pm 8$

0.443

Table 2. Univariate and multivariate analyses of variables associated with in-hospital mortality 


\begin{tabular}{|lllll|}
\hline & \multicolumn{3}{l}{ Univariate analysis } & \multicolumn{2}{l|}{ Multivariate analysis } \\
\cline { 2 - 4 } Variables & HR $(95 \%$ Cl) & P value & HR (95\% Cl) & P value \\
\hline Age & $0.95(0.89-1.08)$ & 0.087 & & \\
\hline Atrial fibrillation & $0.11(0.007-1.743)$ & 0.118 & & \\
\hline IABP insertion & $25.80(2.5-244.52)$ & 0.006 & $3.40(1.0-11.3)$ & 0.042 \\
\hline History of Aortic dissection & $0.079(0.001-6.866)$ & 0.265 & & \\
\hline No Sodium bicarbonate therapy & $0.057(0.005-0.680)$ & 0.023 & & \\
\hline No Vitamin E therapy & $14.296(2.004-101.998)$ & 0.008 & $5.6(1.7-18.3)$ & 0.004 \\
\hline No Allopurinol therapy & $5.58(0.59-52.36)$ & 0.132 & & \\
\hline Sepsis & $0.179(0.02-1.63)$ & 0.127 & & \\
\hline Arrhythmia & $16.31(2.52-105.61)$ & 0.003 & $12.00(3.8-37.7)$ & $<0.001$ \\
\hline Bleeding requiring transfusion & $59.787(1.19-2991.8)$ & 0.04 & $3.40(0.82-14.3)$ & 0.090 \\
\hline Acute renal failure & $9.01(1.11-73.27)$ & 0.04 & $6.70(1.88-24.3)$ & 0.003 \\
\hline Leukocyte $>$ 10.000/uL & $0.78(0.16-3.79)$ & 0.756 & & \\
\hline Hemoglobin $>12$ g/dL & $0.38(0.02-4.92)$ & 0.458 & & \\
\hline Creatinine $>1,2$ mg/dL & $0.43(0.09-2.00)$ & 0.279 & & \\
\hline
\end{tabular}

Table 3. Univariate and multivariate analyses of variables associated with 30-days mortality 


\begin{tabular}{|lllll|}
\hline & \multicolumn{3}{l}{ Univariate analysis } & \multicolumn{2}{l|}{ Multivariate analysis } \\
\cline { 2 - 5 } Variables & $\mathrm{HR}(95 \% \mathrm{Cl})$ & $\mathrm{P}$ value & $\mathrm{HR}(95 \% \mathrm{Cl})$ & P value \\
\hline Onset & $1.00(0.99-1.01)$ & 0.17 & & \\
\hline Rutherford severity & $0.36(0.071-1.88)$ & 0.091 & & \\
\hline Menopause & $4.17(1.20-14.46)$ & 0.024 & $3.20(1.16-8.85)$ & 0.02 \\
\hline IABP insertion & $3.6(0.78-16.47)$ & 0.099 & $4.51(1.14-17.92)$ & 0.03 \\
\hline No vitamin E treatment & & 0.404 & & \\
\hline Acute Renal Failure & $4.13(1.05-16.33)$ & 0.043 & & \\
\hline Arrhythmia & $0.18(0.05-0.62)$ & 0.007 & & $<0.001$ \\
\hline Sepsis & $0.179(0.02-1.63)$ & 0.127 & & 0.05 \\
\hline Arrhythmia & $16.31(2.52-105.61)$ & 0.003 & $0.11(0.04-0.32)$ & \\
\hline Bleeding requiring transfusion & $59.787(1.19-2991.8)$ & 0.04 & $3.77(0.10-14.28)$ & \\
\hline Acute renal failure & $9.01(1.11-73.27)$ & 0.04 & $5.50(1.79-16.95)$ & 0.003 \\
\hline Creatinine $>1,2$ mg/dL & $0.77(0.28-2.10)$ & 0.61 & & \\
\hline
\end{tabular}

Figures 
Mortality of Acute Limb Ischemia Patients 2015-2018

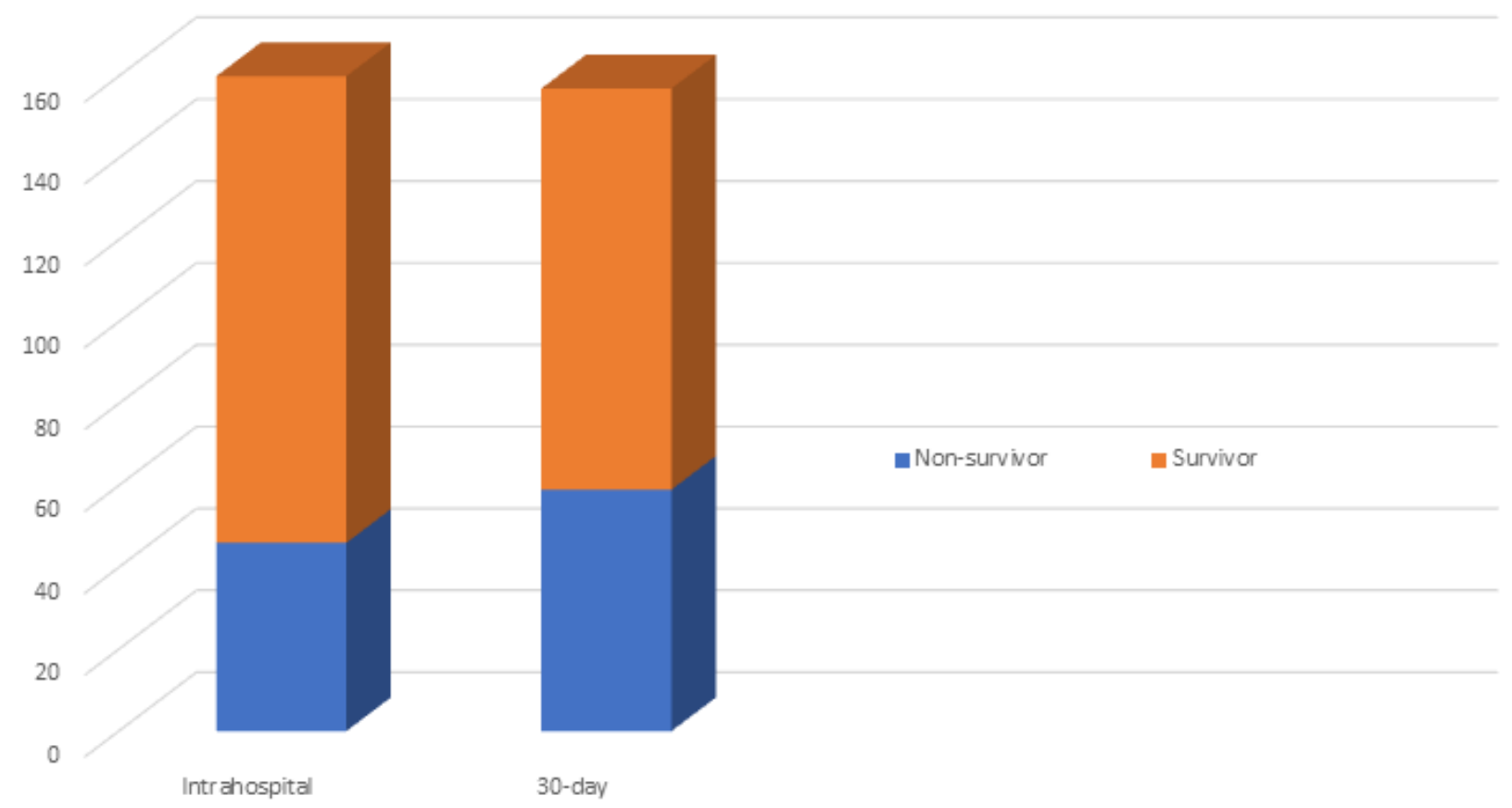

Figure 1

In-hospital and 30-days mortality 